\title{
Original Research Cariology \\ Knowledge of dental caries and salivary factors related to the disease: influence of the teaching-learning process
}

\section{Naiara de Paula \\ FERREIRA-NÓBILO(a) \\ Cínthia Pereira Machado \\ TABCHOURY(b) \\ Maria da Luz Rosário de SOUSA ${ }^{(a)}$ \\ Jaime Aparecido CURY(b)}

(a) University of Campinas - UNICAMP, Piracicaba Dental School, Department of Community Dentistry, Piracicaba, SP, Brazil.

(b) University of Campinas - UNICAMP, Piracicaba Dental School, Department of Physiological Sciences, Piracicaba, SP, Brazil.

Declaration of Interests: The authors certify that they have no commercial or associative interest that represents a conflict of interest in connection with the manuscript.

Corresponding Author:

Maria da Luz Rosário de Sousa

E-mail: luzsousa@fop.unicamp.br

DOI: 10.1590/1807-3107BOR-2015.vol29.0061

Submitted: Ago 04, 2014

Accepted for publication: Jan 13, 2015

Last revision: Apr 17, 2015

\begin{abstract}
Knowledge of factors related to caries and the possible consequences in controlling the disease may show the use of education as a relevant tool for achieving success in terms of dental health maintenance. Therefore, the aim of the present study was to investigate the relationship between acquired knowledge and salivary factors related to dental caries for freshmen students $(n=44)$ and trainees $(n=32)$ of the Piracicaba Dental School. Knowledge about dental caries was evaluated by a discursive questionnaire analyzed by the content analysis technique. Salivary flow and $\mathrm{pH}$, buffer capacity, salivary sucrase activity, microbiological counts (total microorganisms, mutans, and lactobacilli) and inorganic concentration of calcium, phosphorus, and fluoride in saliva were evaluated and compared between groups using the Mann-Whitney test, with a significance of $5 \%$. Trainees demonstrated knowledge of the disease, whereas freshmen showed unspecific and confusing concepts. Among the factors analyzed, statistically significant differences were observed for $\mathrm{pH}$, buffer capacity, sucrase activity, total microorganisms, and calcium and fluoride concentrations in saliva. Knowledge about the disease increases and improves over time during the undergraduate program (highest among trainees); although the students from the final year of the program consume more sugar than those from the previous one, they try to balance this activity with greater exposure to fluorides.
\end{abstract}

Keywords: Dental Caries; Students, Dental; Saliva.

\section{Introduction}

Saliva is often considered to be of low value and is the least known of all human body fluids, ${ }^{1,2}$ however, it prevents proliferation of microbial populations in the oral environment, thus maintaining the integrity of the mineral structure of teeth. ${ }^{2}$ Saliva also presents a modulatory role in the onset and progression of dental caries. Maintenance of oral health by saliva is a direct function of salivary flow because it presents a cleansing (clearance property), buffering (bicarbonate effect), and remineralizing action [supersaturated with calcium $(\mathrm{Ca})$ and inorganic phosphorous $\left.\left(\mathrm{P}_{\mathrm{i}}\right)\right]$ in the oral cavity. For Ericsson and Hardwick, ${ }^{3}$ a rate of stimulated salivary flow greater than $1 \mathrm{~mL} / \mathrm{min}$ is considered normal.

Fermentable sugars are metabolized by biofilm bacteria, resulting in acids that lower the $\mathrm{pH}$, as observed in the Stephan curve. ${ }^{4}$ Saliva shows 
several important effects on biofilm $\mathrm{pH}$ and also leads to its faster return to normal values. These effects are due to the capacity of saliva to dilute (clearance property) and neutralize (buffering property) the acids produced by bacterial fermentation from sugars. In addition, saliva increases the clearance of sugars present in the mouth and dilutes them.

The neutralizing and cleansing effect of saliva has been associated with the immediate effect of demineralization of enamel or dentin in terms of critical $\mathrm{pH}$ for dissolution. However, maintenance of low $\mathrm{pH}$ in the biofilm also selects aciduric and acidogenic bacteria, such as mutans streptococci and lactobacilli. ${ }^{1,2}$

Saliva contains calcium and phosphate ions, which comprise the mineral structure of teeth, and the concentration of these ions in saliva is above the solubility product of the mineral. Therefore, in addition to reducing the dissolution of teeth, saliva tends to repair mineral losses that occur in the oral environment (remineralizing property) every time sugar is ingested (demineralization process). This remineralizing capacity of saliva is increased by salivary flow and by the fluoride effect, ${ }^{5}$ because in the presence of this ion, in addition to the tendency of formation of hydroxyapatite mineral, fluorapatite will also be formed, thus enhancing the remineralization process.

Although changes in diet and behavior of an individual can be better observed in analyses of the biofilm, these changes may also be reflected in saliva, whether from the microbiological point of view or the biochemical one, ${ }^{6,7}$ thus making it a surrogate biomarker of caries.

Thus, one way to consider the effects of the diet on saliva would be by measuring the activity of salivary sucrase, which comprises a group of salivary enzymes that hydrolyze sucrose. When sucrose consumption is high, the activity of salivary sucrase will also be elevated. High salivary sucrase activity (SSA) is considered the one that presents over 10 units of activity of sucrase. ${ }^{8}$

From the perspective of prevention in health care, much has been said about using the tool of education as a strategy to achieve prevention. Little is discussed, however, if individuals have managed to turn the act of knowledge into everyday practices. ${ }^{9}$
Establishment of the relationship between knowledge and adoption of daily practice can help support discussions on prevention programs that are based on health education to be adopted.

Furthermore, when considering health professionals in training, the literature indicates that there is a direct positive relationship between acquired knowledge and clinical practice. ${ }^{10,11,12}$ However, no studies have sought to relate the acquisition of knowledge (one of the constituents of the initial education tool) with the adoption of measures related to self-care practices.

The objective of this study was to investigate the relationship between acquired knowledge about dental caries and salivary factors related to the disease among students of the Piracicaba Dental School (FOP), University of Campinas (UNICAMP) at the beginning and end of the course.

\section{Methodology}

Forty-four students in the first year of the course (at the beginning of classes in February 2011) and 32 students in the final year (at the end of November 2011) took part in this cross-sectional observational study.

Stimulated saliva of students was collected in the morning period (between 10:30 AM and 11:30 AM) during classes without prior notice to students. The inclusion criterion for freshmen students was to be starting the course that year, and for trainees, it was to not have repeated any discipline in the course. Data on foreign students were excluded from the analysis. All students who fulfilled the inclusion and exclusion criteria participated in the study, i.e., $84.6 \%$ of students in the first year and $71.1 \%$ of students in the final year.

The socio-demographic profile of the study population was similar between the freshmen and trainees: mainly females $(86.4 \%$ and $75.0 \%)$, single (100.0\% and $96.9 \%)$, childless (100.0\% and $93.8 \%)$, families living in their own house (84.1\% and $78.1 \%)$, and with family incomes between 5-10 minimum wages ( $45.5 \%$ and $50.0 \%$ ) or above 10 minimum wages (29.5\% and $28.1 \%$, respectively).

Stimulated saliva samples from students were collected using chewing gum base. The weight of saliva produced was determined and divided by the 
duration (min) of saliva collection. The results were expressed in $\mathrm{mL} / \mathrm{min}^{3}$ Saliva $\mathrm{pH}$ was measured directly using a $\mathrm{pH}$ meter (Procyon, model SA 720) coupled to a glass electrode (Thermo Scientific Orion, 8102BNUWP). For calibration, $\mathrm{pH} 4$ and $\mathrm{pH} 7$ standard buffers were used. The accuracy of the $\mathrm{pH}$ meter was checked at regular intervals to ensure that the readings were precise. For determining the buffering capacity of saliva, $0.5 \mathrm{~mL}$ of each saliva sample was placed in a tube containing $1.5 \mathrm{~mL}$ of $5 \mathrm{mmol} / \mathrm{L}$ hydrochloric acid. The tube was shaken to mix the tested saliva and $\mathrm{HCl}$, and the $\mathrm{pH}$ was determined after $5 \mathrm{~min}$ (time to equilibrate dissolved $\mathrm{CO}_{2}$ with that in the air). ${ }^{13,14}$ Microbiological counts of total microorganisms, mutans streptococci, and lactobacilli were performed after dilutions of the saliva, which were inoculated in petri dishes containing blood agar, mitis salivarius agar plus bacitracin, and rogosa agar, respectively, and subsequently incubated at $37^{\circ} \mathrm{C}, 10 \% \mathrm{CO}_{2}$, for $48 \mathrm{~h}$. The results were expressed as colony-forming units (CFU)/mL saliva. ${ }^{15}$ For the determination of fluoride concentration in saliva, the samples were diluted in TISAB II at a ratio of 1:1. Standard fluoride solutions were used to construct the calibration curve. The amount of fluoride in saliva was analyzed with a fluoride-specific electrode (Orion, 96-09) connected to an ion analyzer (Orion, EA-940) ${ }^{16,17}$ Inorganic phosphorous present in saliva was determined using the colorimetric method of Fiske and Subbarow. ${ }^{18}$ The calcium concentration in saliva was assessed using an atomic absorption spectrophotometer (Varian AA 50), calibrated with standards ranging from 0.2 to $2.0 \mathrm{ppm} \mathrm{Ca}{ }^{16,17}$ With regard to SSA, stimulated saliva was centrifuged and the supernatant was incubated with sucrose for $2 \mathrm{~h}$. Blanks of substrate (sucrose), enzyme (saliva), and a tube containing glucose-fructose standards were prepared. The result was expressed in units (nmols of glucose/fructose released $/ \mathrm{min} / \mathrm{mL}$ saliva) of SSA. ${ }^{8}$

A blinded examiner performed the saliva analyses. Salivary factors were analyzed and compared between groups using the Mann-Whitney test, with a significance of $5 \%$.

Knowledge of caries has been reported from the application of the discursive questionnaire with following questions: "What do you mean by dental caries? What causes dental caries? How can we prevent dental caries? Do fillings/dental restorations cure the patient of caries?" The answers were analyzed by the technique of discourse analysis, ${ }^{19}$ and responses were organized in summary tables containing "Core Sense," which refers to the concept, causes, prevention, and treatment of disease; "Answers" in the transcription of some respondents referring to units of meaning; and "Synthesis," which expresses a general summary of the opinions of the study participants. ${ }^{20}$

The research was approved by the Ethics Committee in Research of the FOP/UNICAMP under number 006/2010 protocol, and students who agreed to participate signed the Term of Informed Consent.

\section{Results}

With regard to the salivary factors studied, the difference between groups (freshmen and trainees) was statistically significant for $\mathrm{pH}$, buffering capacity, SSA, total microorganisms, and concentrations of calcium and fluoride (Table 1). The higher activity of SSA and fluoride concentration in the saliva of students from the last year than those in the saliva of students from the first year $(p<0.05)$ suggests that the last year students consume more sugar but are more exposed to fluoride.

The findings on the knowledge of dental caries (concept, cause, and prevention) are summarized in Table 2. On the treatment of the disease, 56.8\% of students in the first year believe that restoration does not cure the patient of the disease, but cannot explain why:

\footnotetext{
"The restoration only eliminates caries, restored part is composed only of resin, and a lack of brushing may induce infiltration in the part that still has teeth."
}

Among the trainees, $81.3 \%$ say that restoration does not cure the patient because they understand that the lesion (treatable) is just a manifestation of the disease and not the disease itself:

\footnotetext{
"Restoration does not cure. It only treats the cavitation, but keeps the patient free from the disease in the future."
}

"Restoration does not cure, only treats the caries lesion." 
Table 1. Salivary factors of students of the first year $(n=44)$ and last year $(n=32)$, FOP/UNICAMP 2011.

\begin{tabular}{|c|c|c|c|c|}
\hline & & Mean \pm S.D. & Min-Max & $p^{*}$ \\
\hline \multirow[t]{2}{*}{ Stimulated salivary flow rate $(\mathrm{mL} / \mathrm{min})$} & First year & $1.42 \pm 0.53$ & $0.60-2.70$ & 0.250 \\
\hline & Last year & $1.75 \pm 0.96$ & $0.50-4.60$ & \\
\hline \multirow[t]{2}{*}{$\mathrm{pH}$} & First year & $7.82 \pm 0.34$ & $6.76-8.63$ & $<0.05$ \\
\hline & Last year & $7.63 \pm 0.25$ & 7.09-8.03 & \\
\hline \multirow[t]{2}{*}{ Buffering Capacity } & First year & $5.29 \pm 1.11$ & $2.91-6.97$ & $<0.05$ \\
\hline & Last year & $4.48 \pm 1.19$ & $2.85-6.31$ & \\
\hline \multirow[t]{2}{*}{ SSA } & First year & $13.23 \pm 11.98$ & $1.41-72.35$ & $<0.05$ \\
\hline & Last year & $19.65 \pm 16.77$ & $4.54-89.38$ & \\
\hline \multirow[t]{2}{*}{ Total microorganisms (CFU/mL 104) } & First year & $4576 \pm 3226$ & $900-12750$ & $<0.001$ \\
\hline & Last year & $14093 \pm 8643$ & $3750-30500$ & \\
\hline \multirow[t]{2}{*}{ Mutans streptococci (CFU/mL 104) } & First year & $40.57 \pm 69.60$ & $0-362.50$ & 0.371 \\
\hline & Last year & $61.83 \pm 210.03$ & $0-1175$ & \\
\hline \multirow[t]{2}{*}{ Lactobacilli (CFU/mL 104) } & First year & $23.98 \pm 122.19$ & $0-800$ & 0.198 \\
\hline & Last year & $4.65 \pm 16.15$ & $0-87.50$ & \\
\hline \multirow[t]{2}{*}{ Ca Concentration (mmol) } & First year & $0.47 \pm 0.25$ & $0.17-1.58$ & $<0.001$ \\
\hline & Last year & $1.01 \pm 0.39$ & $0.17-1.96$ & \\
\hline \multirow[t]{2}{*}{$\mathrm{P}_{\mathrm{i}}$ Concentration (mmol) } & First year & $8.97 \pm 3.80$ & $4.02-23.56$ & 0.064 \\
\hline & Last year & $9.61 \pm 2.17$ & $4.41-14.45$ & \\
\hline \multirow[t]{2}{*}{ F Concentration $(\mu \mathrm{g} / \mathrm{mL})$} & First year & $0.017 \pm 0.005$ & $0.010-0.031$ & $<0.001$ \\
\hline & Last year & $0.075 \pm 0.104$ & $0.015-0.459$ & \\
\hline
\end{tabular}

* Mann-Whitney test

SSA: salivary sucrase activity

\section{Discussion}

Dental caries is a multifactorial disease that presents a necessary factor (biofilm accumulation), negative (fermentable sugars) and positive (exposure to fluorides) determinant factors, biological modulators (saliva), and social (socioeconomic status) factors. ${ }^{21}$

In the present research, salivary factors were studied, but the isolated effect of each factor on caries should be critically analyzed with caution, considering the multifactorial characteristic of the disease. Several studies refer to the analysis of microbiological, biochemical, and inorganic factors analyzed in the present research to study dental caries. However, factors such as salivary flow, $\mathrm{pH}$, buffering capacity, and calcium and phosphate concentrations are physiological factors, i.e., the individual has no direct control over them.

The microbiological counts also refer to an individual factor, although the increase in mutans streptococci and lactobacilli counts is associated with the development and progression of caries and sugar consumption. This increase refers to individual values of the condition before the development of disease.
Among the factors analyzed, only SSA and fluoride concentration can be controlled by an individual. SSA increases with sucrose consumption, ${ }^{22}$ and our results showed greater activity in the saliva of students from the last year than those from the first, suggesting greater consumption of sugar (Table 2). Fluoride concentration in saliva may indicate exposure to fluorides, arising mainly from consumed fluoridated water and fluoridated toothpaste, and a higher concentration was found in the saliva of students from the last year (Table 2).

In the present research, the students showed normal salivary flow and saliva $\mathrm{pH}$ close to 7 (neutral $\mathrm{pH}$ ); however, the average buffering capacity of both groups (freshmen and trainees) was below the value that is considered as a good buffering capacity, namely $\mathrm{pH}$ 5.5. ${ }^{13,14}$

Based on findings of SSA, the trainees have consumed more sugar than the freshmen, which can be attributed to diet change during college. Students often carry their meals out of their homes, neglecting the need for balanced meals, consuming higher amounts of processed products with high sugar 
Table 2. Knowledge about dental caries of students ( $n=76)$, FOP/UNICAMP 2011.

\begin{tabular}{|c|c|c|c|}
\hline Core Sense & & Answers & Synthesis \\
\hline \multirow[t]{2}{*}{ CONCEPT } & First Year & $\begin{array}{c}\text { "Micro-organism that develops as the oral hygiene will become } \\
\text { increasingly precarious." } \\
\text { "Disease that affects the teeth of people who do not maintain } \\
\text { certain oral hygiene." } \\
\text { "Infectious disease caused by the proliferation of bacteria release } \\
\text { acids that erode some layers of the teeth." } \\
\text { "Disease in the tooth that causes rotting on the damaged parts." }\end{array}$ & $\begin{array}{l}\text { - Difficulty in developing concept } \\
\text { - Confusion between disease and caries lesion } \\
\text { - Relate with dental caries (lack of) oral hygiene } \\
\text { - Persistence of the concept of disease transmission } \\
\text { - Association between diet and dental caries }\end{array}$ \\
\hline & Last year & $\begin{array}{c}\text { "Imbalance in the process of DES-RE tooth caused by the action of } \\
\text { acids produced by plaque." } \\
\text { "Multifactorial disease, where it is necessary that the person } \\
\text { possesses the cariogenic microorganisms, one Ideta rich in sugar } \\
\text { and the time required for the formation of the disease there." } \\
\text { "Imbalance that occurs between the process of DES-RE, where DES } \\
\text { is higher due to higher production of acid from the fermentation of } \\
\text { fermentable carbohydrates." }\end{array}$ & $\begin{array}{l}\text { - Concepts most elaborated } \\
\text { - Predominance of biological concept, } \\
\text { associated with the DES-RE process } \\
\text { - Some respondents cite the multifactorial } \\
\text { concept restrictive (Keyes triad) }\end{array}$ \\
\hline \multirow[t]{2}{*}{ CAUSE } & First Year & $\begin{array}{l}\text { "Shortness of oral hygiene." } \\
\text { "Accumulation of food debris present in the spaces between the teeth." } \\
\text { "Action of certain microorganisms, such as bacteria, which feed on } \\
\text { sugar consumed by us." }\end{array}$ & $\begin{array}{l}\text { - Association between food debris and cleaning } \\
\text { - A few referred to the sugar consumption }\end{array}$ \\
\hline & Last year & $\begin{array}{l}\text { "The accumulation of carbohydrates with certain bacteria cause acid } \\
\text { production and subsequent demineralization of the structures." } \\
\text { "Favorable microbiota, substrate (diet) and poor hygiene." } \\
\text { "Cariogenic diet, salivary buffer capacity, microbiota and } \\
\text { socio-economic factors." }\end{array}$ & $\begin{array}{l}\text { - Consumption of sugar } \\
\text { - Lack of hygiene } \\
\text { - Few cited social determinants involved }\end{array}$ \\
\hline \multirow[t]{2}{*}{ PREVENTION } & First Year & $\begin{array}{c}\text { "Good dental hygiene, beyond the control of feeding on excess } \\
\text { carbohydrates." } \\
\text { "Brush your teeth thoroughly and make flossing regularly." } \\
\text { "Oral hygiene: brushing and flossing." }\end{array}$ & $\begin{array}{l}\text { - Clean (brushing and flossing) } \\
\text { - Minority showed a reduction in sugar } \\
\text { consumption }\end{array}$ \\
\hline & Last year & $\begin{array}{c}\text { "Cutting the causal factors." } \\
\text { "Brushing your teeth properly and removing the biofilm using } \\
\text { fluoridated products." } \\
\text { "Brushing and diet control." }\end{array}$ & $\begin{array}{l}\text { - Clean } \\
\text { - Diet Control } \\
\text { - Use of fluoride products }\end{array}$ \\
\hline
\end{tabular}

content. Likewise, a higher fluoride concentration was observed in the saliva of trainee students, which may indicate a greater engagement thereof with the regular use of fluoride toothpastes, perhaps in an attempt to offset the high intake of sugar, because the development of the disease is well known to this group.

The freshmen showed a better understanding of dental caries than lay people even when they had not had any contact with the subjects for the first year of college and the present study was conducted during the early days of the course program. However, the present study observed that these freshmen had some level of difficulty in developing concepts and a persistent confusion between signs of the disease (the lesions) and disease itself, as well as the concept of transmissibility.

These mistaken views are resolved over the course of the program as the students of the last year have demonstrated knowledge of the development of the disease. These students presented biological concepts, local factors of disease (process of de-remineralization), or Keyes triad (comprising a restrictive multifactorial concept), considered to be interactions of multiple factors. However, these individuals did not consider the social determinants involved in the disease.

The present research showed that the knowledge of caries increased over the course program, and through the analysis of salivary factors of students, we found that graduates consume more sugar and are exposed to more fluoride than the freshmen. Increased exposure to fluoride among trainees possibly occurs as an attempt to balance the consumption of sugar in this group, which has more knowledge about the caries process and the mechanism of fluoride-reducing demineralization and enhancing enamel-dentine remineralizaton. 
The present study has a number of limitations. First, we evaluated salivary factors that are surrogate factors of caries, suggesting that in future, the progression or arrest of caries lesions in graduating students should be evaluated. Another limitation was the type of experimental design used; the study was not prospective, suggesting that the same students should be evaluated during the course program to confirm the results of this cross-sectional study. Furthermore, markers as dental biofilm composition and dietary sugar consumption should be assessed. As earlier described, a limitation of this study was that the investigation reported only salivary factors, although several other factors may influence the development of caries. Another limitation involves the research design; the present study was cross-sectional and may reflect the reality of the investigated sample. Therefore, it would be worthwhile to study salivary factors

\section{References}

1. FDI Working Group 10, CORE. Saliva: its role in health and disease. Int Dent J. 1992 Aug;42: 4 Suppl 2:287-304.

2. Cury JA, Tenuta LMA, Tabchoury CPM. Saliva, chewing gum and oral health. In: Centenary of the APCD. São Paulo: Napoleão; 2011. 179-190. Portuguese.

3. Ericsson Y, Hardwick L. Individual diagnosis, prognosis and counselling for caries prevention. Caries Res. 1978;12 Suppl 1:94-102.

4. Stephan RM. Changes in hydrogen-ion concentration on tooth surfaces and in carious lesions. J Am Dent Assoc. 1940 May;27(5):718-23.

5. Cury JA, Tenuta LMA. Enamel remineralization: controlling the caries disease or treating early caries lesions? Braz Oral Res. 2009;23 Suppl 1:23-30.

6. Mandel ID. The role of saliva in maintaining oral homeostasis. J Am Dent Assoc. 1989 Aug;119(2):298-304.

7. Herrera JL, Lyons MF 2nd, Johnson LF. Saliva: its role in health and disease. J Clin Gastroenterol 1988 Oct;10(5):569-78.

8. Karjalainen S, Karjalainen M, Forrester D. Physiologic variation of sucrase activity and microbial counts in human saliva. Scand J Dent Res. 1992 Apr;100(2):111-6.

9. Zhu L, Petersen PE, Wang HY, Bian JY, Zhang BX. Oral health knowledge, attitudes and behavior of adults in China. Int Dent J. 2005 Aug;55(4):231-41.

10. Forrest JL, Horowitz AM, Shmuely Y. Dental hygienists' knowledge, opinions, and practices related to using a longitudinal investigation, as well as also other markers of disease such as biofilm, daily diet, and clinical variables in relation to the knowledge acquired during the course of the disease during each year of graduation in dentistry.

\section{Conclusions}

Knowledge of dental caries increases over the course program (higher among trainees). Although the students from the last year consume more sugar than those from the first year, they try to balance this activity with a greater exposure to fluorides, as indicated in analysis of salivary factors.

\section{Acknowledgments}

The study was supported by Fundação de Amparo à Pesquisa do Estado de São Paulo - FAPESP scholarship awarded to the first author (Processes 2009/12370-1; 2011/24042-9).

oral and pharyngeal cancer risk assessment. J Dent Hyg. 2001 Fall;75(4):271-81.

11. Khami MR, Virtanen JI, Jafarian M, Murtomaa H. Oral health behavior and its determinants amongst Iranian dental students. Eur J Dent Educ. 2007 Feb;11(1):42-7.

12. Calderón SH, Gilbert P, Zeff RN, Gansky SA, Featherstone DB, Weintraub JA, et al. Dental students' knowledge, attitudes, and intended behaviors regarding caries risk assessment: impact of years of education and patient age. J Dent Educ. 2007 Nov;71(11):1420-7.

13. Frostell G. A colourimetric screening test for evaluation of the buffer capacity of saliva. Swed Dent J. 1980;4(3):81-6.

14. Wikner S, Nedlich U. A clinical evaluation of the ability of the Dentobuff method to estimate buffer capacity of saliva. Swed Dent J. 1985;9(2):45-7.

15. Aires CP, Del Bel Cury AA, Tenuta LMA, Klein MI, Koo H, Duarte S, et al. Effect of starch and sucrose on dental biofilm formation and on root dentine demineralization. Caries Res. 2008 Sep;42(5):380-6.

16. Vogel GL, Chow LC, Brown WE. A microanalytical procedure for the determination of calcium, phosphate and fluoride in enamel biopsy samples. Caries Res. 1983;17(1):23-31.

17. Tenuta LMA, Del Bel Cury AA, Bortolin MC, Vogel GL, Cury JA. $\mathrm{Ca}, \mathrm{Pi}$ and $\mathrm{F}$ in the fluid of biofilm formed under sucrose. J Dent Res. 2006 Sep;85(9):834-8.

18. Fiske $\mathrm{CH}$, Subbarow Y. The colorimetric determination of phosphorus. J Biol Chem 1925;66:375-400. 
19. Rocha D, Deusdará B. Content analysis and discourse analysis: approaches and departures in the (re)construction of a trajectory. ALEA. 2005 July-Dec;7(2):305-22. Portuguese.

20. Nico LS, Bocchi SCM, Ruiz T, Moreira RS. [The grounded theory as a methodological approach for qualitative research in dentistry]. Cienc Saude Coletiva. 2007 MayJun;12(3):789-97. Portuguese.
21. Ferreira-Nóbilo NP, Sousa MLR, Cury JA. Conceptualization of dental caries by undergraduate dental students from the first to the last year. Braz Dent J. 2014 Jan-Feb;25(1):59-62.

22. Karjalainen S, Karjalainen M, Söderling E. Effect of sucrose rinses on the oral microflora and on salivary sucrase activity. Caries Res. 1993;27(1):38-42. 